\title{
Exploring The Link Between Women Economic Empowerment And Energy Conservation
}

\author{
Musarrat Jabeen \\ Faculty of Contemporary Studies \\ National Defense University \\ Saima Bibi \\ Department of Development Studies \\ COMSATS Institute of Information Technology \\ Awais Ali Shah \\ Department of Electrical Engineering \\ COMSATS Institute of Information Technology
}

\begin{abstract}
Women and energy conservation strategies purport earning, borrowing or the skills for energy conservation. The datasets for household energy management do not identify the grant of economic decision making to women delegate households by the earning men households as an entry point to initiate and encourage the healthy mindsets for energy conservation. The objective of this study is to explore the link between economic decision making and the women economic empowerment for energy conservation and to assess the energy conservation trends among the economically empowered women. Delphi focused proved $70 \%$ correlation between energy women economic empowerment based on economic decision making and energy conservation. The energy conservation trends found positive $80.20 \%$ and negative $19.80 \%$ in economically empowered women, positive $55.80 \%$ and negative $44.20 \%$ in not economically empowered women. The study suggests that the economic decision making is a significant tool for women economic empowerment; and women economic empowerment does not depend only on the facts that women earn, have micro finance loans or skills to manage or produce energy. The study is a contribution to organize civil society to conserve energy for sustainable societies and cities.
\end{abstract}

Keywords: Women's Economic Empowerment, Energy, Conservation, Pakistan.

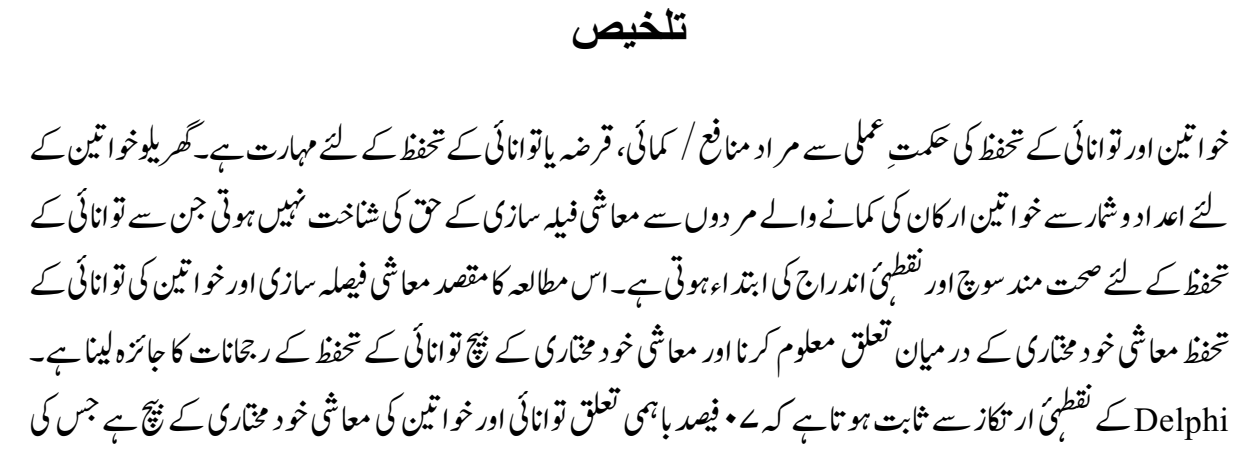




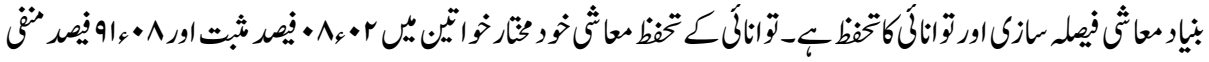

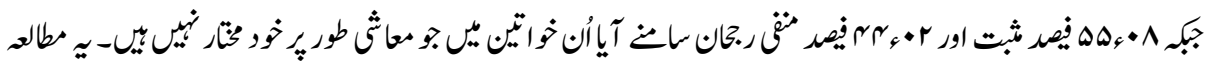

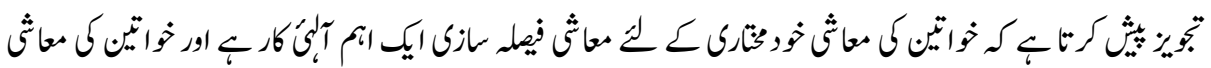

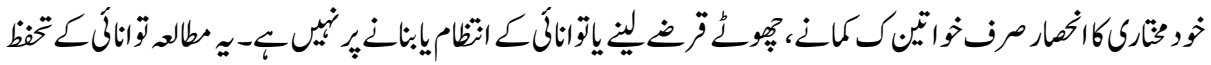

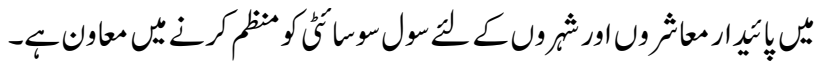

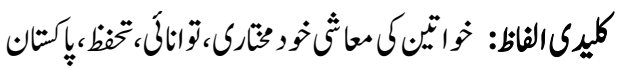

\section{Introduction}

Studies have shown strong correlations between energy, sustained economic growth, and human welfare, underscoring the need for energy security. Concerns for environment have added new pressures on energy users for the sustainable use of energy. Jackson (2006) states that all countries in the world are vying with each other to secure their energy supplies from known sources of traditional energy and also discover new, cheaper and sustainable sources of energy. Since 2006 in Pakistan on average, the demand supply deficit was around 5,000 MW it touched the peak of over 7,000 megawatt (MW) July 2014. Out of 67 Million Tonnes of Oil Equivalent (MTOE) of total primary energy mix for 2013-14, 46.4 per cent share is of natural gas, 35 per cent oil, 11.4 per cent hydro, 5.4 per cent coal and 02 per cent nuclear (Ministry of Planning and Development, 2014). Disproportionate reliance on the imported oil, that is, 85 per cent of the total oil supply, is exerting a strain on the balance of payments besides making the energy mix unfavorable. Due to controversies about major dams e.g. Kalabagh dam Pakistan harnesses only 6750 MW (11.25 per cent) out of its hydro potential of about 60,000 MWs. Thermal power is relied upon natural gas, expensive furnace oil and high speed diesel oil in the electricity generation, adversely affecting its affordability in due course. Danish (2014) commented, "Pakistan is mired in an acute energy crisis with immense implications for both the nation's floundering economy and its volatile security situation." Energy shortages have cost the country up to $4 \%$ of gross domestic product (GDP) over the past few years causing the shutdown of industry and impeding the investments in development and infrastructure (Pakistan Economic Survey, 2010-11). In 2005, the Energy Security Action Plan (2005-2030) was approved to meet the requirements of Pakistan's Vision 2030 for reliable and quality energy supplies. The main objective of the plan was to enhance energy supply through an optimal mix of all resources including hydropower, oil, gas, coal, nuclear and renewable energy such as wind and solar. Conventional energy policies have tended to focus on energy supply, with little attention to manage the demand for energy. It is imperative to establish institutions and stipulate mechanisms and procedures for effective conservation and efficient use of energy in Pakistan (The Pakistan Energy Efficiency \& Conservation Act, 2014). In Pakistan the lapses in energy management systems at all levels are correlated to un-thoughtful decisions and practices at national- 
provincial-district levels due to its centralized wisdom and concentrating more on the supply side. Rationale of this study rests with demand management by applying the idea of energy conservation through women economic empowerment.

\section{Energy Conservation}

Saving energy, increasing efficiency leads to reduce energy consumption. The drivers of energy conservation are: to care for the society and future generations, and money saving through less energy bill. Conservation helps us to mitigate the adverse impacts associated with energy production and consumption. These include air pollution, acid rain and global warming, oil spills and water pollution, loss of wilderness areas, construction of new power plants, foreign energy dependence and the risk of international conflict over energy supplies. Energy conservation extends the lifetime of equipment and reduces the maintenance cost by operating in less maximum capacity.

Energy conservation depends on style of energy use as it is used invisibly. The energy systems are complex regarding daily practices. In social terms the system is also limited in terms of appliances over which it is based. The energy systems continuously use gas or electricity until stopped manually or by automatic control set by human factor. Comparatively the energy conservation regarding these systems is difficult as the use of liquid or solid fuels is finite as it can be seen, weighed or poured. The energy systems at domestic level involve many factors; infrastructure, social norms, comfort level and the control options. (Lutzenhiser, 1993; Shove, 2003; Bugess and Nye, 2008) establish in their studies the importance of factors are normally within the control of households. The frequent highlights in this regard are the daily routines and practices, comfort standards and expectations.

Wilhite (2008) concluded the study, "Combined roles of knowledge, routines, and technology influence the energy use actions. The energy conservation interventions are specific to time and space and they cannot be applied universally. The evidences suggest we may not conserve energy with the application of technology and economic factors alone the sociological and cultural factors drive the energy system as well."

\section{Women Economic Empowerment}

The literature bearing the thought of energy and women economic empowerment propose the two ideas; first is that how much the energy services are available to women and the second is economic status of women determines the type and style of energy use. Cecelski, (2008) studied that the reduction and eventual eradication of poverty is tied to access to modern energy services; because the household activities like cooking, heating, lighting, and irrigation depend on energy. It is found that income plays significant role in energy consumption and conservation patterns. The higher income earning households 
more convenient and efficient sources of energy and people with les income use less efficient and less convenient sources of fuel wood.

Economic behavior depends on social and financial prompts and effects the energy use practices (Schultz et al, 2008). Energy consumption is inelastic as it is relevant to inelastic energy demand e-g, energy demand for transportation to approach the education and health services, and to live in though weather conditions; but social systems of household economy affect the energy utilization system as well. The energy conservation related practices depend on decision to investment in energy efficient measures in home (Lutzenhiser, 2002). Fischer, in her 2008 energy conservation review highlighted the features of interaction and choice for households based on economic factors for energy conservation.

Saline (2012) argues regarding economic empowerment, "Both the ability to succeed and advance economically and the power to make and act on economic decisions." The study bends to social psychology to establish the working definition of women economic empowerment in conservation perspective of self and the society (see Box 1). In this study the ability of delegate women households in making and acting the economic decisions depends on the decision making power granted by the male earning households. Box 1-Conservation and social value orientation.

Source: Murphy, (2011)

"In social psychology, social value orientation (SVO) is a person's preference about how to allocate resources (e.g. money) between the self and another person. SVO corresponds to how much weight a person attaches to the welfare of others in relation to the own. Social value includes social capital as well as the subjective aspects of the citizens' well-being, such as their ability to participate in making decisions that affect them."

\section{Link between Women Economic Empowerment and Energy Conservation}

There exists a link between energy conservation and women economic empowerment. Women with the decision power regarding finances will utilize the energy more economically than the other women without this power. Women with control in running house expenditures will try to limit expenditures through economic utilization of energy by making the others to do the same. Human activities are identified as crucial aspect while aiming to reduce energy demand. Consumption can be seen as the part of human activity that spends energy (Daly, 1996). Energy consumption is unavoidable (Korsunova, 2010). Consumption can be distinguished in two domains. One relates consumer behavior to the context and infrastructure emphasizing physical assets, taxation and pricing policies, technological innovations etc. The second reduces consumer behavior to be the end of psychological and social drivers (Mont and Power, 2009). The energy system can be considered as socio-technical system focusing on operating conditions, actor 
dependencies and organizational aspects (Jonsson et al., 2011). The combination of purchase and product-use decisions is crucial (Princen, 2006). Gynther et al. (2011) argue in this context that $90 \%$ of energy-related behavior is habitual driven by attitudes and contextual factors. Literature is scarce on energy conservation efforts directed at household level. The latent incentives like the economic empowerment without earning as social construct for energy conservation is nominal. Literature provides a grey area in respect of delegate women's role in energy conservation with and without economic empowerment. The broader objective of the study is to contribute innovative social capital into energy conservation societal strategic planning. The specific objectives are as follows:

1. To identify the correlation between economic decision making and women economic empowerment for energy conservation in women delegate households.

2. To assess the level of energy conservation drivers and activities in women delegate households.

The measureable items are: the income of the population, the existing level of thinking to conserve energy for state, society, future generations, and for the less energy bill under the caption of drivers for energy conservation; opting warm clothing, harvesting sun energy, purchasing and using energy efficient appliances under the caption of activities for energy conservation.

To highlight the women economic empowerment based on making and acting economic decision making the following are the questions of study:

1. What is the significance of relationship between economic decision making and women economic empowerment for energy conservation?

2. What is the level of energy conservation drivers and activities existing in women delegate households?

\section{Methodology}

The methods the guiding principle was: the implied economic power to make and act upon economic decision impacts the drivers and activities as behavior to conserve the energy. In this study the behavior is themed under two captions; drivers for energy conservation and activities for energy conservation.

\section{Theoretical Framework for Exploring the Correlation between Women Economic Empowerment and Energy Conservation}

The energy conservation may not be conditioned only with the energy conservation technologies but it is contextual to social construct of energy utility. Societal promotion of women economic empowerment matters for energy conservation by reducing energy consumption or using less energy for a constant service. The variables in this study are the following: 
- Socio-economic construct for energy conservation = change variable

- Energy conservation = outcome variable

- Women economic empowerment = linking variable

The theoretical framework of this research measures the link between women economic empowerment and energy conservation (see Fig. 1).

Fig: 1

Theoretical framework for exploring the link between energy conservation and women economic empowerment

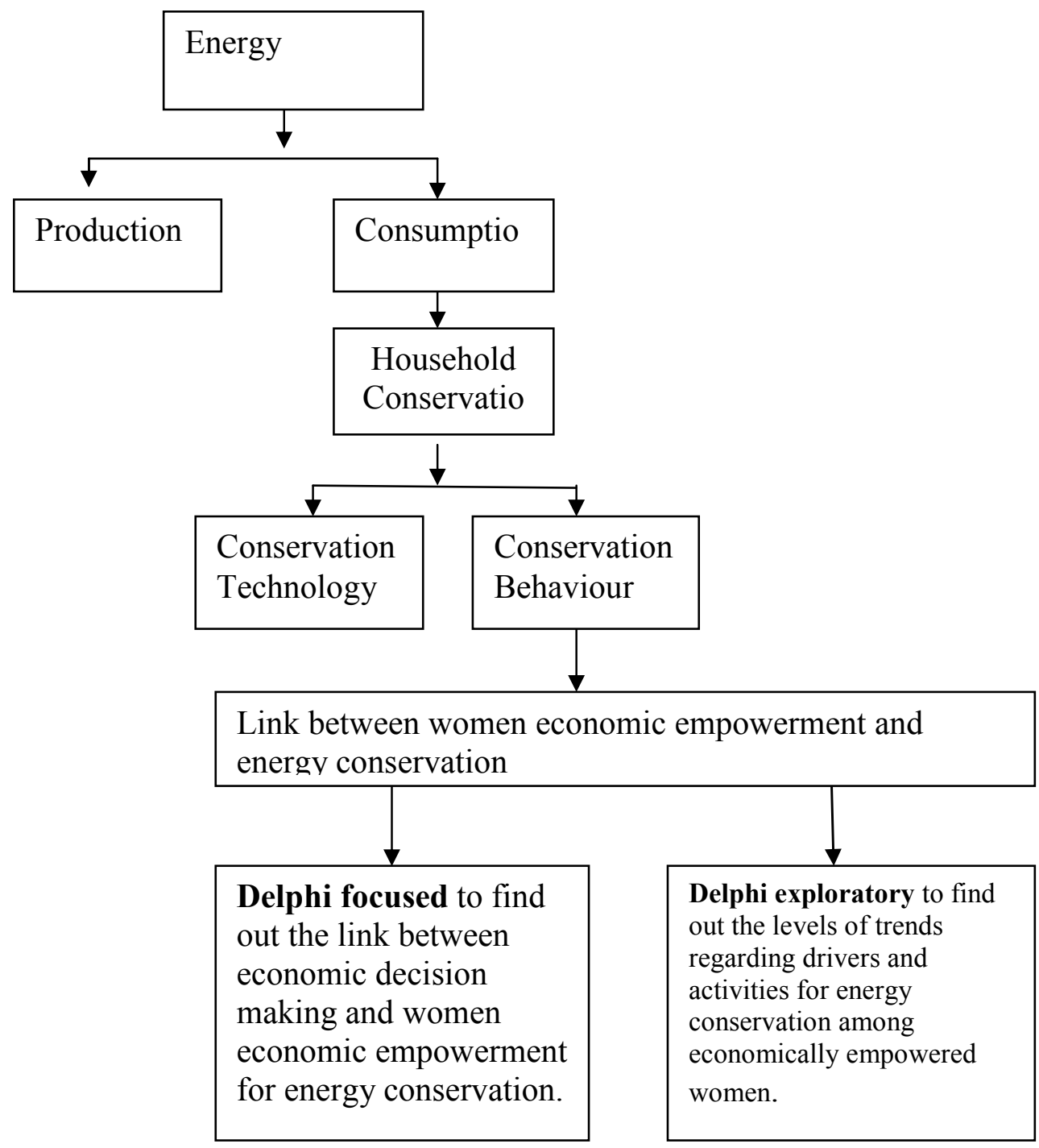

Source: extracted by author 


\section{Methods of Data Collection}

Human behavior persists diversely to respond different challenges as per their societal and personal dispositions in contact to economic empowerment. The scheme of this study tries to explore the link between women economic empowerment and energy conservation among the delegate households in terms of economic decision making. Delphi focused activity was held in February, 2015 and Delphi exploratory activity was organized and undertaken from February 2015 to June 2015.

\section{Questionnaires}

Delphi focused: The questionnaire is designed to get the consensus from 16 experts to explore and identify the link between women economic empowerment and energy conservation. It was composed of following three questions:

- Round 1. Can there be a link between energy conservation and women economic empowerment?

- Round 2. How much is the possibility to practice the link between energy conservation and women economic empowerment?

- Round 3. How much can be the intensity to practice the link between energy conservation and women economic empowerment?

On the basis of results of the first question in round 1 the question is constructed for second round and on the basis of results of the second question in round 2 the question is constructed for the third round.

Delphi exploratory: The questionnaire is designed specific to energy conservation behavioral patterns. The questions were worded simple and clear, the options provided an opportunity for easy and unambiguous response. In total, 100 respondents were selected on the bases of purposive sampling from delegate women households to assess the habitual behviour for energy conservation. 50 delegate households were selected having full liberty to make and act economic decisions while the other 50 were not having power to make and act economic decisions though both the categories were not earning. The structured questionnaire is composed of two themes: drivers for energy conservation and activities for energy conservation (see Annexure 1).

Drivers for energy conservation include concepts of thinking which may drive the human behviour pertinent to some activity means the energy conservation.

- Thinking to reduce energy consumption to help the society is positive $(+)$ as it leads to less energy consumption. Not thinking to reduce energy consumption to help the society is negative (-) as it does not lead to less energy consumption.

- Thinking to reduce energy consumption to help the future generations is positive $(+)$ as it leads to less energy consumption. Not thinking to reduce energy consumption to help the future generations is negative (-) as it does not lead to less energy consumption. 
- Thinking to reduce energy to reduce energy crisis of Pakistan is positive $(+)$ as it leads to less energy consumption. Not thinking to reduce energy consumption to better response to energy crisis of Pakistan is negative (-) as it does not lead to less energy consumption.

- Less dependency on energy is positive $(+)$ as it leads to less energy consumption. More dependency on energy is negative (-) as it does not lead to less energy consumption.

- Non satisfaction with energy bill is positive $(+)$ as it leads to opt the activities for reducing the bill. Satisfaction with energy bill is negative (-) as it does not lead to opt the activities for reducing the bill.

Activities for energy conservation include:

- Opting for warm clothing is positive $(+)$ as it leads to less consumption of energy. Not opting for warm clothing is negative (-) as it does not lead to less consumption of energy.

- Harvesting natural light is positive $(+)$ as leads to less energy consumption. Not harvesting natural light is negative (-) as it does not lead to less energy consumption.

- Purchasing energy efficient appliances is positive $(+)$ as leads to less energy consumption. Not purchasing energy efficient appliances is negative (-) as it does not lead to less energy consumption.

- Using energy efficient appliances is positive $(+)$ as leads to less energy consumption. Not using energy efficient appliances is negative (-) as it does not lead to less energy consumption.

- Switching off of the appliances instead of standby is positive $(+)$ as it leads to less consumption of energy. Not switching off of the appliances instead of standby is negative (-) as it does notlead to less consumption of energy.

\section{Observations}

Data collected through structured questionnaires was corroborated on the basis of personal observations.

\section{Data Analysis}

Data was analyzed by using mode (frequency distribution, standard deviation, SPSS (20) is used to compute the values and significances.

\section{Findings and Discussion}

The energy conservation depends on the women economic empowerment delegated by earning households on the bases of trust to make and act economic decisions to manage the household economy. The findings are leveled under three captions. 


\section{Relation between Women Economic Empowerment and Energy Conservation}

The study explored and identified the link between women economic empowerment and energy conservation. 70 percent results tell us that there is a substantial link between energy conservation and the women economic empowerment. The comments are concluded from the open ended questions answered by the 16 expert respondents (see Box 2).

\section{Box 2-Delphi Focused Results}

$\checkmark \quad$ There is a significance relationship between economic decision making and economic empowerment for energy conservation A women with the decision power in contact to finances will utilize the energy more economically than the other women without this power. Women with control in running house expenditures will try to limit expenditures through economic utilization of energy by making the others to do the same.

$\checkmark \quad$ Women can be empowered through trust and involvement and in domestic management of resources in terms of finances and hence results in abstention or efficient utilization of energy resources.

$\checkmark \quad$ Electronic and print media, seminars and workshops, and curriculum can be used to realize and gain the benefits of link between energy conservation and women economic empowerment. It can be practiced at household and commune levels leading to societal change.

Women can be empowered through involvement and in domestic management of resources in terms of finances and hence results in abstention or efficient utilization of energy resources.

\section{Relationship between Women Economic Empowerment and Drivers for Energy Conservation}

The study measured the income of the sample population, the drivers for energy conservation (see Table 1-3). The women economically empowered are found with positive trend $77.2 \%$ and negative trend $22.8 \%$ in their thinking drivers for energy conservation. While the women economically not empowered are found with positive trend $62 \%$ and negative trend $38 \%$ in their thinking drivers for energy conservation.

Table: 1

Average monthly income of the respondents

\begin{tabular}{|c|c|c|c|c|c|}
\hline $\begin{array}{l}\text { Monthly Income } \\
\text { of the respondents }\end{array}$ & $\mathbf{N}$ & Minimum & Maximum & Mean & $\begin{array}{c}\text { Std. } \\
\text { Deviation }\end{array}$ \\
\hline
\end{tabular}


Table: 2

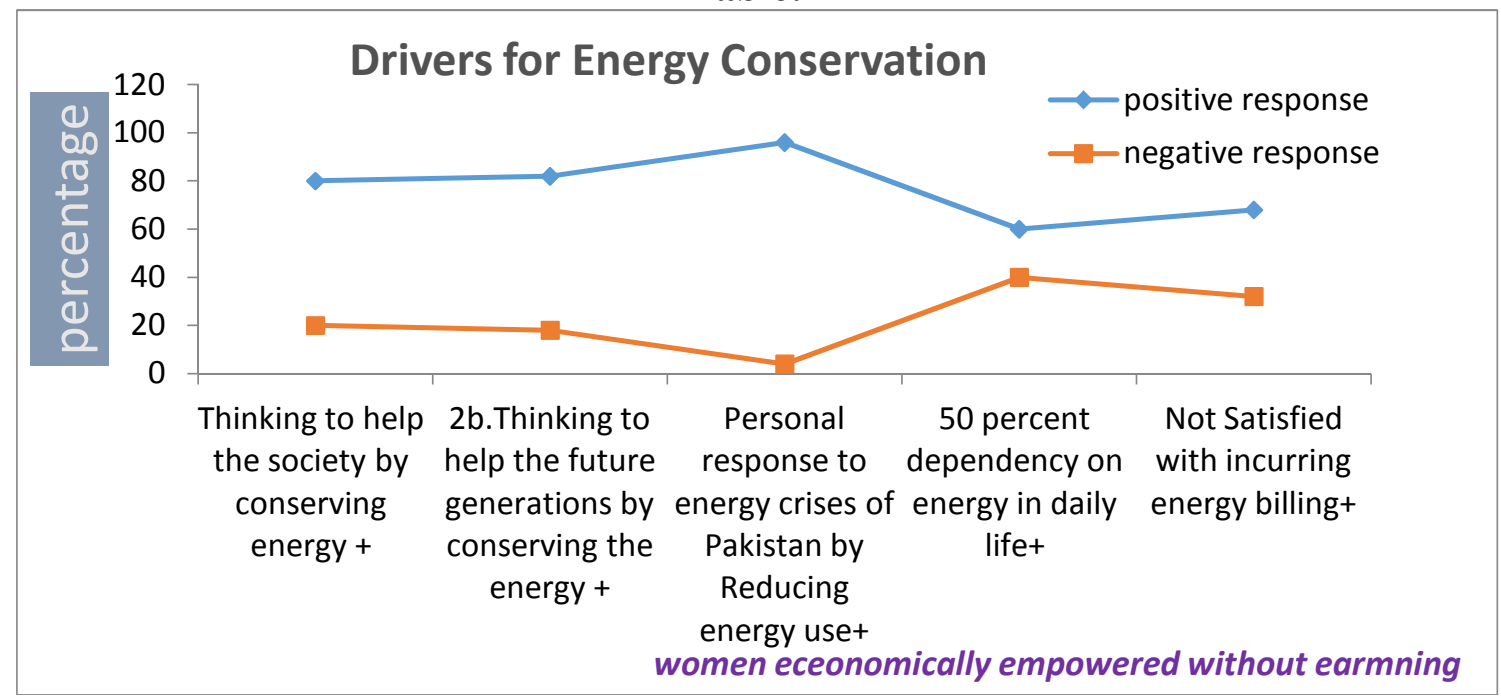

Table 3

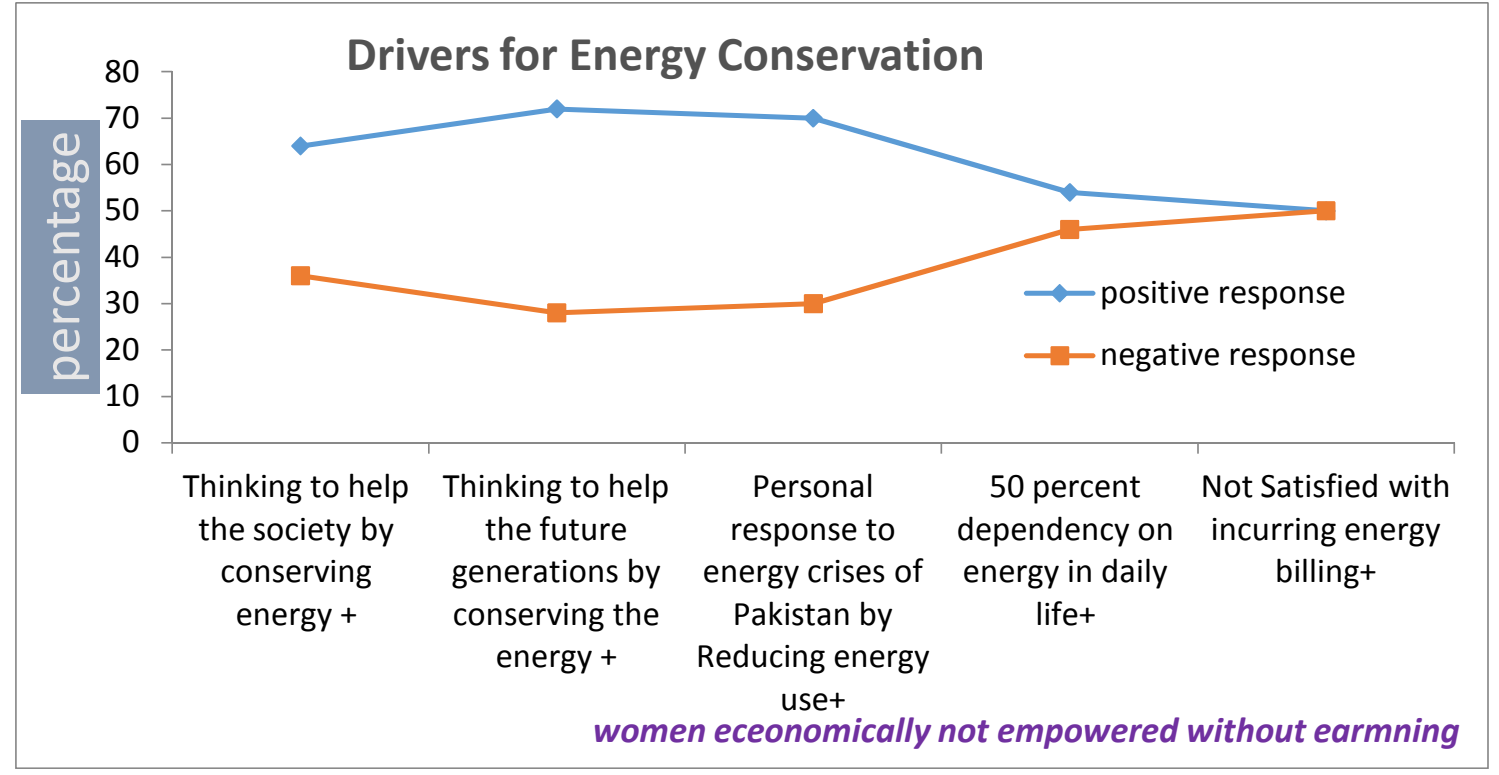

\section{Relationship between Women Economic Empowerment and Activities for Energy Conservation}

Energy conservation activities are the support to social energy conservation system. It is found that there is significant relation between women economic empowerment and the activities for energy conservation. The women economically empowered are found with positive trend $83.2 \%$ and negative trend $16.8 \%$ in their activities for energy conservation. While the women economically not empowered are found with positive trend $49.6 \%$ and 
negative trend $54.4 \%$ in their activities for energy conservation (see Table 4-5). The study gives a practical approach for earlier energy conservation studies. According to Kiplinger, with turning off the lights when there is no need of, you can save several dollars without sacrificing your comfort. "People get excellent return on their investment through energy efficiency" (Kiplinger 2001). Energy conservation has been prompted as a win- win option, it provides benefit to both environment energy consumers, and society with the net economic gain (Grubb, 1992). Reduced energy bills free up income to be spent on other critical needs (Ryan and Chambel, 2012). There are two main benefits of energy conservation that individuals may consider.

Table: 4

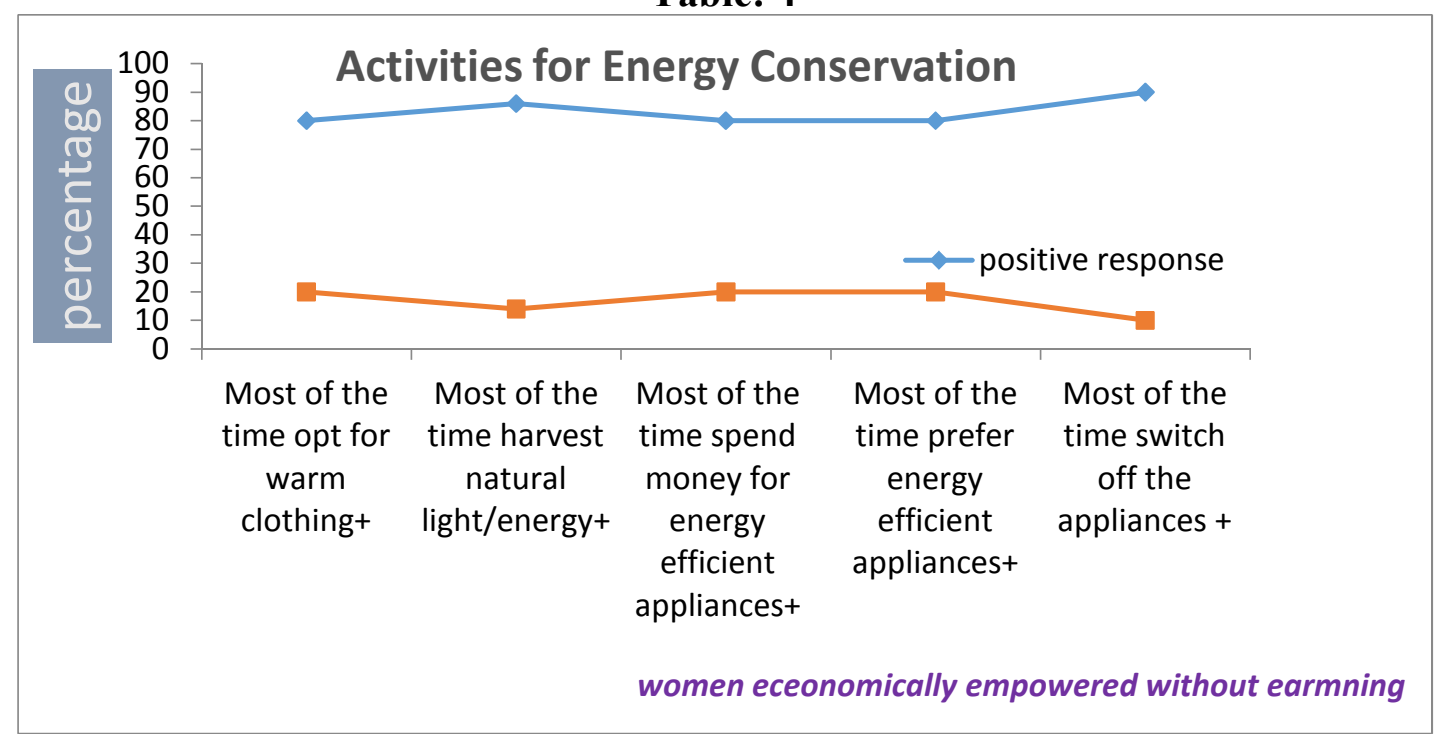

\section{Table 5}

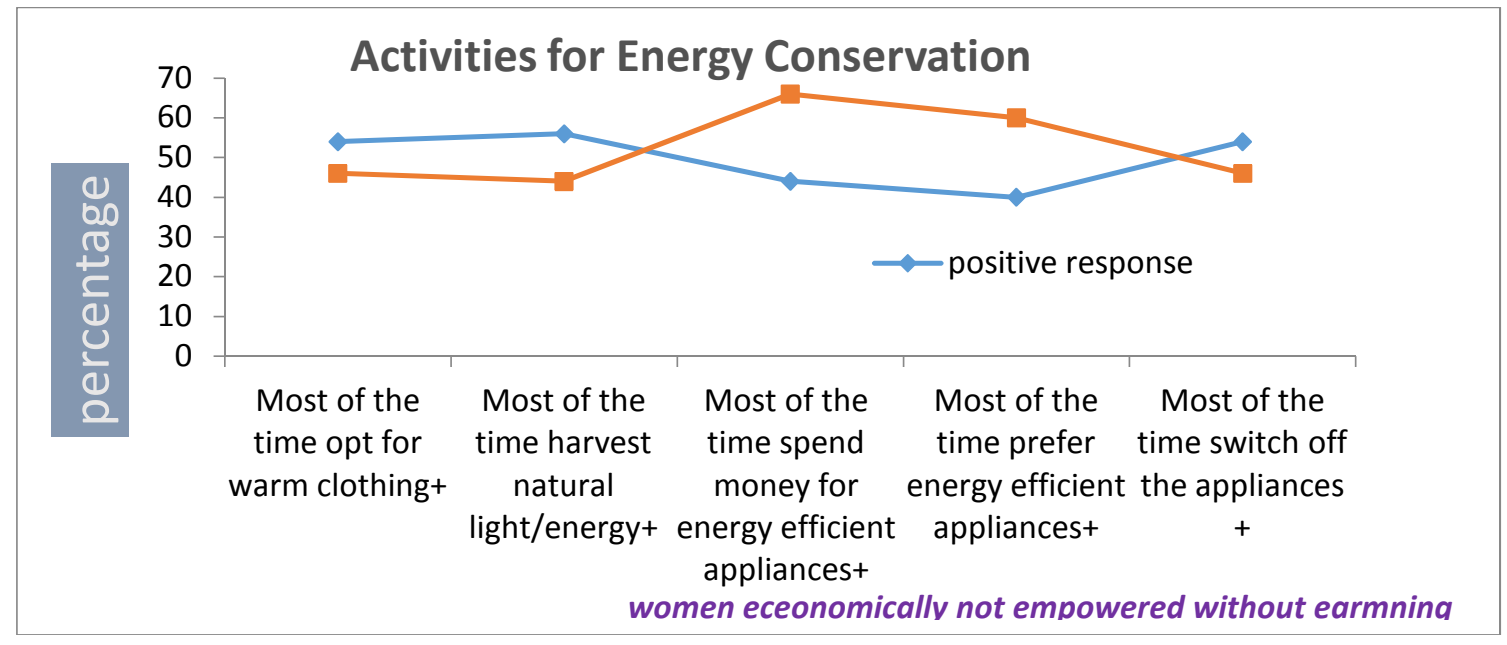




\section{Conclusions and Recommendations}

The facts make us to underscore that women economic empowerment promotes energy conservation though they are not earning. The Delphi focused $70 \%$ results establish the significance link between women economic empowerment and energy conservation. The Delphi Exploratory measurement about the manifestation for energy conservation among economically empowered women by using the concepts of drivers and activities for energy conservation allow us that the delegate households trusted by the earning households are better energy conservatives. Women's involvement in energy conservation is found to be significantly positively related to make and act economic decisions. The energy conservation trends found positive $80.20 \%$ and negative $19.80 \%$ in economically empowered women, positive $55.80 \%$ and negative $44.20 \%$ in not economically empowered women. The social value orientation (SVO) of drivers for energy conservation were itemized as the existing level of thinking to conserve energy for state, society, future generations, and for the less energy bill under the caption of drivers for energy conservation; opting warm clothing, harvesting sun energy, purchasing and using energy efficient appliances under the caption of activities for energy conservation. The outcome of this study is advantageous as it considers the economically empowered women the source of motivation for constructing civil society to conserve energy. The idea to empower women without earning will substantiate the sustainability of the society. The existing socio-economic practices are limited in its posture and practice of women economic empowerment. The idea of women economic empowerment held by this study needs a mindset change that women may prove better delegate household by having the economic empowerment without going out for earning. The society and media should highlight the men rendering economic power to their women delegate households at home as the source of energy conservation for sustainable societies.

\section{References}

Burgess, J. \& Nye, M. (2008). Re-Materialising Energy Use through Transparent Monitoring Systems, Energy Policy, vol.36:12, pp.4454-4459.

Cecelki, Elibeth. (2000). Enabling Equitable Access to Rural Electrification: Current Thinking and Major Activities in Energy, Poverty and Gender. Retrieved on Sep 30, 2016 from http://www.sarpn.org/genderenergy/resources/cecelski/ energypovertygender.php

Daly, H. (1996). Beyond Growth: The Economics of Sustainable Development. Beacon Press; Boston. 
Danish, Muhammad (2014). Worst Scenario of Pakistan Energy, htt://chaybakhtian.blogspot.com/2014/06/worst-scenario-of-pakistan-energy.html, accessed on Jan 201, 2015.

Grubb, M. J. (1992). Reply to Brookes, Energy Policy, pp.783-85.

Gynther, L., Makkonen, I, \& Smits, A. (2011). Evaluation of European Energy Behavioral Change Programs, Energy Efficiency, DOL 10.1007/s 12053-0119115-9.

Jackson, T. (2006). Challenges for Sustainable Consumption Policy, In: Jackson, Tim (Ed). Tthe Earthscan Reader in Sustainable Consumption, p. 109-128. Earthscan, London \& Sterling (VA).

Jonsson, D., Gustaffson, S., Wangel, J., Hojer, M., Lundqvist, P. \& Svane, O. (2011). Energy at Your Service: Highlighting Energy Usage Systems in the Context of Energy Efficiency Analysis. Energy Efficiency, 4:355-369.

Lutzenhiser, L. (1993). Social and Behavioural Aspects of Energy Use Annual Review of Energy and Environment, vol.18, pp.247-289

Lutzenhiser, L (2002). Marketing household energy conservation: the message and the reality. National Academy Press, Washington DC.

Kiplinger, (2001). People Get Excellent Return on their Investment through Energy Efficiency, htt://www.kiplinger.com/article/investing/T041-C000-S002-10-greatmutual-funds-that-deliver-high-income.html Accessed on May 23, 2015.

Korsunova, A. (2010). Encouraging Energy Conservation with 'No Hard Feelings'. A Two-part Analysis of Communication between Energy Companies and Finnish Households. Jyvaskyla Studies in Business and Economics, Volume 95, Jyvaskyla Finland.

Murphy, Ryan O. (2011). Measuring Social Value Orientation, Judgment and Decision Making, vol.6:8, pp.771-781.

Ministry of Planning and Development www.pc.gov.pk/wp-content/uploads/2015/ 06/Ch18, Accessed on Feb 03, 2015.

Mont, O. \& Power, K. (2009). Understanding Factors that Shape Consumption. European Topic Centre on Sustainable Consumption production, Copenhagen (Denmark). 
Pakistan Economic Survey, 2010-11, Economic Adviser's Wing, Finance Division, Government of Pakistan, Islamabad

Princen, T. (2006). Consumption and its Externalities: Where Economy Meets Ecology. In: Jackson, Tim (Ed). The Earthscan Reader in Sustainable Consumption, Earthscan, London \& Sterling (VA), pp.50-66.

Ryan, L. \& N. Campbell (2012). Spreading the Net: The Multiple Benefits of Energy Efficiency Improvements, OECD/IEA.

Salinee, Worabantoon (2012). Measuring and Evaluating Women's Economy Empowerment, Birmingham, Report by Governance and Social Development Resource Centre.

Shove, E. (2003). Comfort, Cleanliness and Convenience: The Social Organization of Normality, Oxford, Berg Publishers.

Schultz, PW, Nolan, JM, Cialdini, RB, Goldstein, NJ \& Griskevicius, V. (2008). The Constructive, Destructive and Reconstructive Power of Social Norms, Psychological Sceince, vol.18:5, pp.429-434.

The Pakistan Energy Effieciency \& Conservation Act, 2014, www.enercon.gov.pk/ index.php?option=com_content\&view. Accessed on $4^{\text {th }}$ March, 2015.

Wilhite, H. (2008). New Thinking on the Agentive Relationship between End-Use Technologies and Energy Using Practices. Energy Efficiency 1 (1) 


\section{Annexure 1. Exploring link between women economic empowerment and energy conservation}

\section{Questionnaire (Delphi Exploratory) \\ Categories of Respondents:}

\begin{tabular}{|l|l|l|}
\hline $\mathbf{1}$ & $\mathbf{2}$ \\
\hline $\begin{array}{l}\text { Women economically empowered } \\
\text { without earning }\end{array}$ & $\begin{array}{l}\text { Women economically not empowered } \\
\text { without earning }\end{array}$ \\
\hline
\end{tabular}

Section A

Drivers for Energy Conservation

Tell us to assess the drivers for energy conservation

1. Would you like to reduce energy consumption for helping the society as the energy you save can be used by others?
(a) Yes
(b) No

2. Would you like to reduce energy consumption for helping the future generations as the energy you conserve can be used by next generations?
(a) Yes
(b) No

3. How would you like to respond to energy crises of Pakistan in your personal capacity?

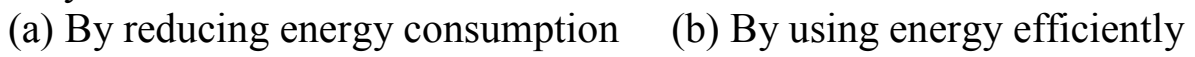

4. How much you are dependent on energy in your daily life activities?
(a) $50 \%$
(b) $80 \%$

5. Are you satisfied with the monthly billing of electricity and gas as percentage of your total expenses?
(a) Yes
(b) No

Section B

Activities for energy conservation

Tell us to identify the activities for energy conservation

1. Do you opt warm clothing to reduce the energy consumption in winter?
(a) Sometimes
(b) Most of the time

2. Do you conserve energy by operating windows and doors as per timings of the day and weather conditions in summer and winter?
(a) Sometimes
(b) Most of the time

3. Do you like to spend on energy efficient appliances?
(a) Sometimes
(b) Most of the time

4. Do you like to use energy efficient appliances?
(a) Sometimes
(b) Most of the time 
5. Do you arrange the complete switch off of the appliances instead of standby? Sometimes

(b) Most of the time

Dr. Musarrat Jabeen is an Associate Professor in the Faculty of Contemporary Studies, National Defense University, Islamabad, Pakistan.

Saima Bibi is MS Student in the Department of Development Studies, COMSATS Institute of Information Technology, Abbottabad, Pakistan.

Awais Ali Shah is MS Student in the Department of Electrical Engineering, COMSATS Institute of Information Technology, Abbottabad, Pakistan. 